\title{
Prediction of vertical bearing capacity of waveform micropile
}

\author{
Y.-E. JANG*, B. KIM*, C. WANG† and J.-T. HAN $\ddagger$
}

This study proposes a predictive equation for bearing capacity considering the behaviour characteristics of a waveform micropile that can enhance the bearing capacity of a conventional micropile. The bearing capacity of the waveform micropile was analysed by a three-dimensional numerical model with soil and pile conditions obtained from the field and centrifuge tests. The load-transfer mechanism of the waveform micropile was revealed by the numerical analyses, and a new predictive equation for the bearing capacity was proposed. The bearing capacities of the waveform micropile calculated by the new equation were comparable with those measured from the field and centrifuge tests. This validated a prediction potential of the new equation for bearing capacity of waveform micropiles.

KEYWORDS: design; finite-element modelling; footings/foundations

Published with permission by the ICE under the CC-BY 4.0 license. (http://creativecommons.org/licenses/by/4.0/)

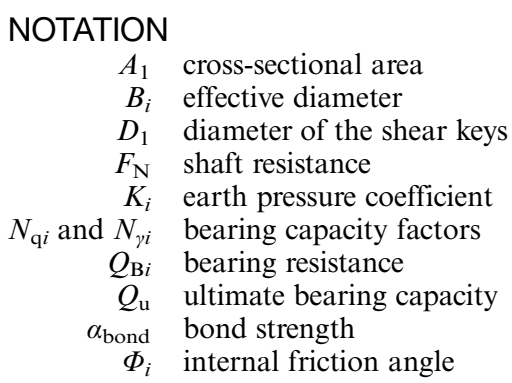

\section{INTRODUCTION}

Micropiles are small-diameter, bored cast-in-place piles that insert high-strength steel reinforcement into grout with a diameter of 100-300 mm, which were first used in the 1950s in Italy. Micropiles can be easily used in construction sites with limited space access and are widely used in various applications such as new construction, foundation reinforcement and seismic foundation because they can be installed with relatively compact equipment.

Micropiles' reinforcement transfers load from the upper parts to the ground through the grout, and resist the loads by frictional resistances between the grout and the surrounding soil. This shaft resistance is considered as the micropiles' design bearing capacity, and the end bearing capacity is not taken into account due to the small diameter. For the construction of the micropiles, bearing strata below compressible soils are considered as the socket length to acquire bearing capacities as shown in Fig. 1(a). However, this construction procedure has a disadvantage that the pile length has to be increased as the thickness of the soil strata

Manuscript received 23 November 2018; first decision 8 April 2019; accepted 21 May 2019.

Published online at www.geotechniqueletters.com on 15 July 2019.

*School of Urban and Environmental Engineering, Ulsan National Institute of Science and Technology, Ulsan, Korea. $\uparrow$ School of Geo-Space Engineering, University of Science and Technology, Daejeon, Korea.

tDepartment of Infrastructure Safety Research, Korea Institute of Civil Engineering and Building Technology, Gyeonggi, Korea. increases. Therefore, there have been studies to obtain additional bearing capacities by modifying the shape of the micropiles (Vickars \& Clemence, 2000; Livneh \& El Naggar, 2008; Kim et al., 2016).

By extending these previous efforts, Jang \& Han (2014, 2015) proposed a waveform micropile by integrating a conventional micropile and the jet grouting method as shown in Fig. 1(b). This method creates a wave-shape grout named as the shear key by making some parts of the grout larger, resulting in the enhancement of the shaft resistance at the contact area between the grout and the soil. In general, the diameter of the shear key $D_{1}$ is $500 \mathrm{~mm}$, the diameter of the pile shaft $D_{2}$ is $300 \mathrm{~mm}$ and the length of the shear key $L$ and the spacing $S$ are defined as functions of the shear key diameter $D_{1}$. Jang \& Han $(2018,2019)$ validated the construction feasibility of this waveform micropile and enhancement of shaft resistance at soil layers using waveform shear keys. They also pointed out that it is necessary to have a design guideline considering the shape of the pile as the key design factor $\alpha_{\text {bond }}$ suggested for the conventional micropile (FHWA, 2005) is applicable only for the pile shaft and not the shear key part of the waveform micropile. Therefore, this study performed a three-dimensional (3D) numerical simulation based on field test conditions and load test results, and proposed predictive equations for design bearing capacities considering the load-bearing mechanism from the simulations.

\section{NUMERICAL ANALYSIS MODEL Modelling and input properties}

A 3D finite-element method (FEM) software, Plaxis 3D (Brinkgreve et al., 2012), was used for analysing the vertical load resistance mechanism of micropiles. Soil conditions and shapes of micropiles for numerical analyses were determined according to the conditions of the field test performed by Jang \& Han (2018). The Mohr-Coulomb model, an elasto-plastic model, was adopted. The material properties shown in Table 1 were estimated from the standard penetration test (SPT) and $N$ values were obtained by Jang \& Han (2018). When the elastic modulus $E$ (Bowles, 1988; KHBD (MCT, 2005)) and the internal friction angle $\Phi$ (Peck et al., 1953; Dunham, 1954; Kitazawa et al., 1959; 


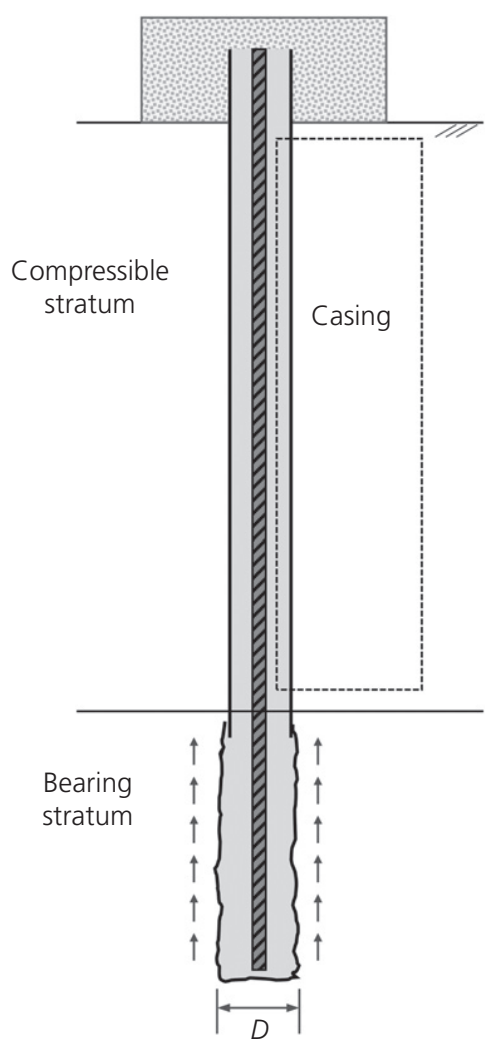

(a)

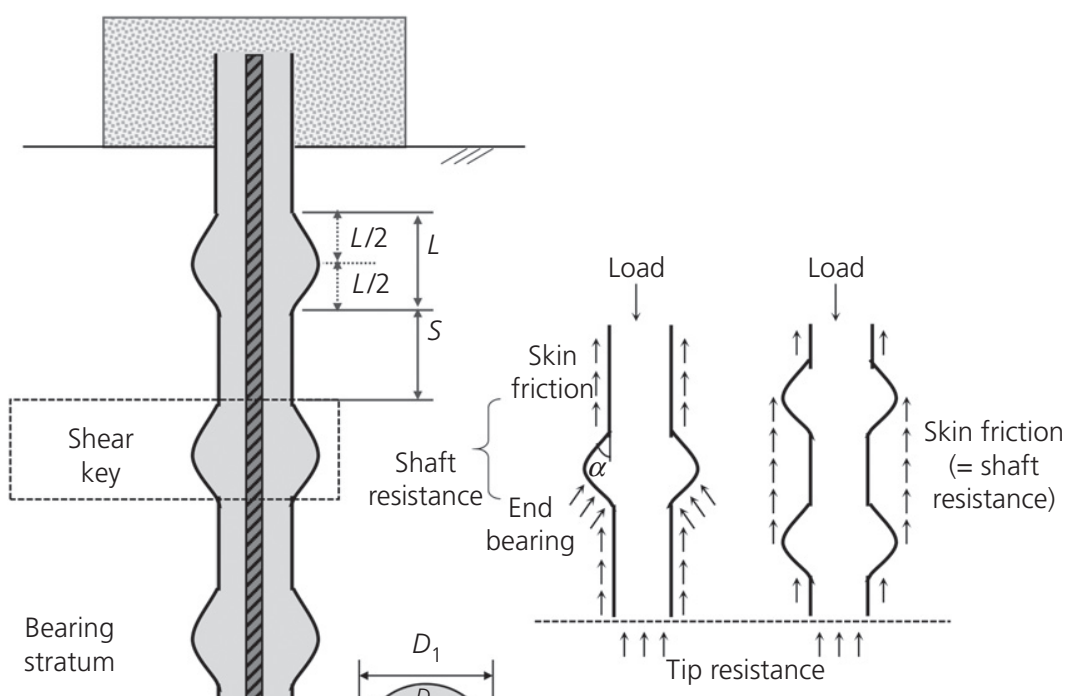

(ii) Load-bearing mechanism

$D$ : diameter of conventional micropile

$D_{1}$ : diameter of shear key $(500 \mathrm{~mm})$

$D_{2}$ : diameter of pile shaft $(300 \mathrm{~mm})$

$L:$ height of shear key

S: spacing between shear keys

$\alpha$ : angle of shear key with respect to pile shaft (b)

Fig. 1. Conceptual drawing of a conventional micropile and a waveform micropile: (a) conventional micropile, (b) waveform micropile (source: modified from Jang \& Han, 2019)

Table 1. Soil material properties for numerical analysis

\begin{tabular}{|c|c|c|c|c|c|c|c|}
\hline \multicolumn{2}{|l|}{ Layer } & \multirow{2}{*}{$\begin{array}{c}\text { Unit weight } \\
\gamma: \mathrm{kN} / \mathrm{m}^{3}\end{array}$} & \multicolumn{2}{|c|}{ Elastic modulus } & \multirow{2}{*}{$\begin{array}{c}\text { Poisson's ratio } \\
v\end{array}$} & \multirow{2}{*}{$\begin{array}{c}\text { Cohesion } \\
c: \mathrm{kPa}\end{array}$} & \multirow{2}{*}{$\begin{array}{c}\text { Internal friction } \\
\Phi: \operatorname{deg}\end{array}$} \\
\hline Type & Depth: $m$ & & $E: \mathrm{MPa}$ & $E_{\text {inc }} *: \mathrm{MPa} / \mathrm{m}$ & & & \\
\hline Fill & $0-4 \cdot 5$ & $18 \cdot 0$ & $22 \cdot 8$ & - & $0 \cdot 3$ & - & 30 \\
\hline Deposit & $4 \cdot 5-7 \cdot 5$ & $19 \cdot 0$ & $34 \cdot 8$ & $11 \cdot 2$ & $0 \cdot 3$ & - & 35 \\
\hline Weathered soil & $7 \cdot 5-8 \cdot 0$ & $20 \cdot 0$ & $51 \cdot 6$ & $248 \cdot 4$ & $0 \cdot 3$ & 10 & 33 \\
\hline Weathered rock & $8 \cdot 0-15 \cdot 0$ & $21 \cdot 0$ & $450 \cdot 0$ & - & $0 \cdot 28$ & 50 & 39 \\
\hline
\end{tabular}

${ }^{*} E_{\mathrm{inc}}$, increment of stiffness per unit of depth.

KHBD (MCT, 2005)) were calculated using existing equations using $N$ values, then the best-fitting value in the numerical analysis was selectively used within the calculated result ranges.

The Mohr-Coulomb model and the embedded beam element were used for the grout and steel rebar of the micropile, respectively. The embedded beam element is appropriate for simulating the behaviour of the grout and steel rebar simultaneously because it can define behaviour with surrounding elements by using the interface values for the vertical and horizontal shaft resistance and point resistance (Brinkgreve et al., 2012).

The strength of a grout $(c)$ is taken to be half of the uniaxial compression strength for the 20 grout samples taken from the waveform micropile during the field test by Jang \& Han (2018). After iterative analyses using a range of the measured uniaxial strengths from 6.0 to $14.4 \mathrm{MPa}$, $c=8600 \mathrm{kPa}$ was selected as the best estimate for the field test results. Other material properties of the grout and steel rebar are presented in Table 2 .

Figure 2(a) shows the 3D finite-element mesh of the waveform micropile and soil stratum. The detailed elements of the waveform micropile and interface are shown in Fig. 2(b). The size of the numerical model is $10 \mathrm{~m}$ in the $x$ and $y$ directions and $15 \mathrm{~m}$ in the $z$ direction. The boundary is horizontally fixed in the $x$ and $y$ directions and the bottom boundary is fixed in the vertical direction. A distance between the pile tip and the bottom of the soil model is 30 times the diameter of the micropile shear key, $500 \mathrm{~mm}$. Therefore, one can judge that there are no boundary effects while vertical loads are applied to the micropile.

The numerical model for the micropile consists of elements of inner steel rebar, waveform grout and the interface between the pile and soils. A strength reduction factor of the interface element, $R_{\text {int }}$, can be considered as that of granular and cohesive soils or less. A $R_{\text {int }}$ value of 0.67 was used in this study (Garbacz, 2010).

\section{Analysis of numerical modelling results}

Numerical analyses were conducted to generate a loadsettlement curve of the pile using the displacement-control method. The final value of the prescribed displacement in the numerical analysis was $35 \mathrm{~mm}$, equal to the final 
Table 2. Material properties of the waveform micropile for numerical analysis

\begin{tabular}{l|c|c|c|c|c|l}
\hline Material & $\begin{array}{c}\text { Elastic modulus, } \\
E: \mathrm{GPa}\end{array}$ & Cohesion, $c: \mathrm{kPa}$ & $\begin{array}{c}\text { Unit weight, } \\
\gamma: \mathrm{kN} / \mathrm{m}^{3}\end{array}$ & Poisson's ratio, $v$ & $\begin{array}{c}\text { Diameter, } \\
D: \mathrm{mm}\end{array}$ & Model \\
\hline Steel rebar & 210 & - & $78 \cdot 5$ & $0 \cdot 1$ & $300 / 500$ & Embedded beam \\
Grout & 24 & 4300 & $23 \cdot 5$ & $0 \cdot 167$ & $63 \cdot 5$ & Mohr-Coulomb \\
\hline
\end{tabular}

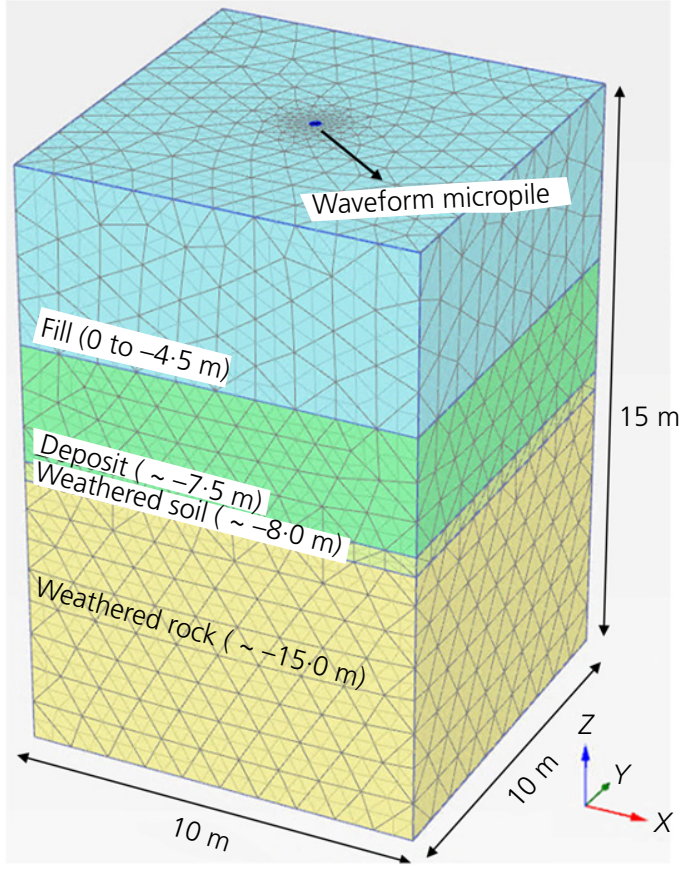

(a)

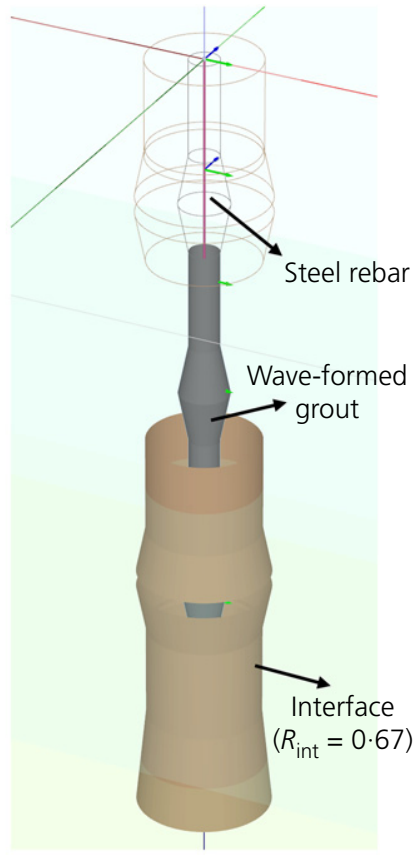

(b)

Fig. 2. Numerical model for the waveform micropile and soil stratum: (a) cross-section view of the 3D finite-element mesh for the waveform micropile and soil stratum, (b) detailed view of the pile and interface

displacement estimated from the field test. Figure 3 shows that the load-settlement curve estimated by the numerical analysis is in good agreement with that measured from the field load test. This represents that the material properties assigned to the model are appropriate.

The development of the micropiles' resistance was observed by ground displacement characteristics around the pile until a final displacement of $35 \mathrm{~mm}$. It is found that the initial displacement of the pile occurs at the top and tip of the pile as the load increases. After sufficient settlement, the displacement of the ground at the shear keys and the shaft under the ground remarkably increases. Particularly, displacement below the shear keys becomes larger than that near the shaft at the final displacement stage, which corresponds to the ultimate bearing capacity.

Figure 4(a) shows the direction of the total displacement of the soils near the pile at a final displacement of $35 \mathrm{~mm}$. Most of the soil displacement near the shaft takes place vertically towards the bottom. On the contrary, displacement at the upper part of the shear keys is focused towards the pile. Soil displacement at the lower part of the shear keys is widely distributed and has more horizontal components, resulting in the resistance zones below the shear keys. The resistance zone by a shear key can be defined as the triangle $\Delta b c d$ as shown in Fig. 4(b).

\section{A DESIGN EQUATION FOR THE CALCULATION OF THE} BEARING CAPACITY OF THE WAVEFORM MICROPILE

The numerical simulation of the waveform micropile revealed that the additional resistance against a vertical

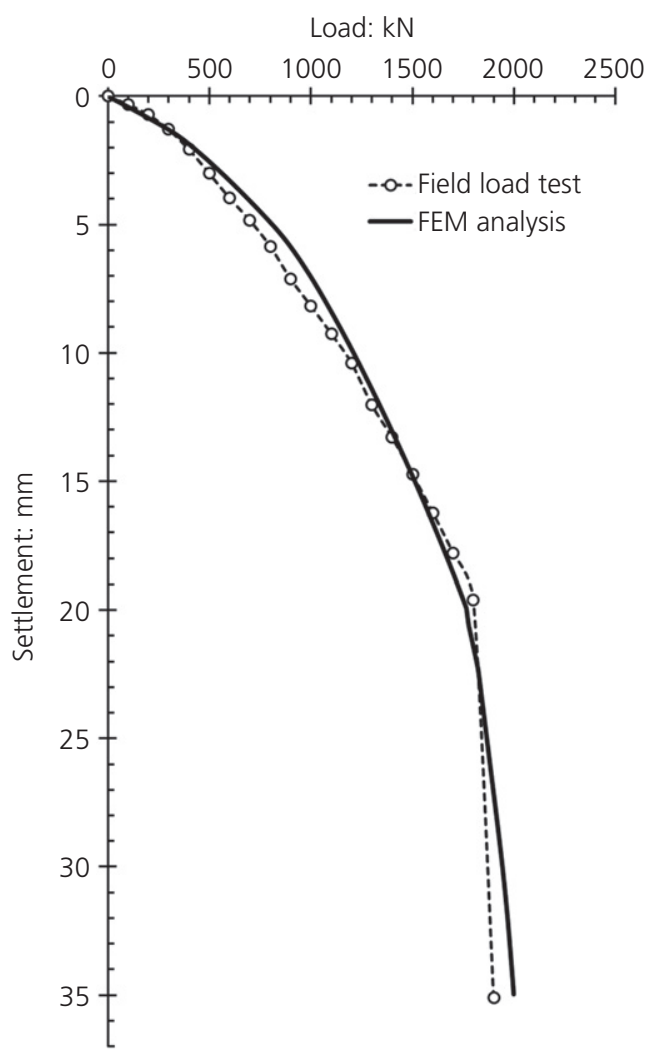

Fig. 3. Load-settlement curves from the numerical analysis and the field load test 


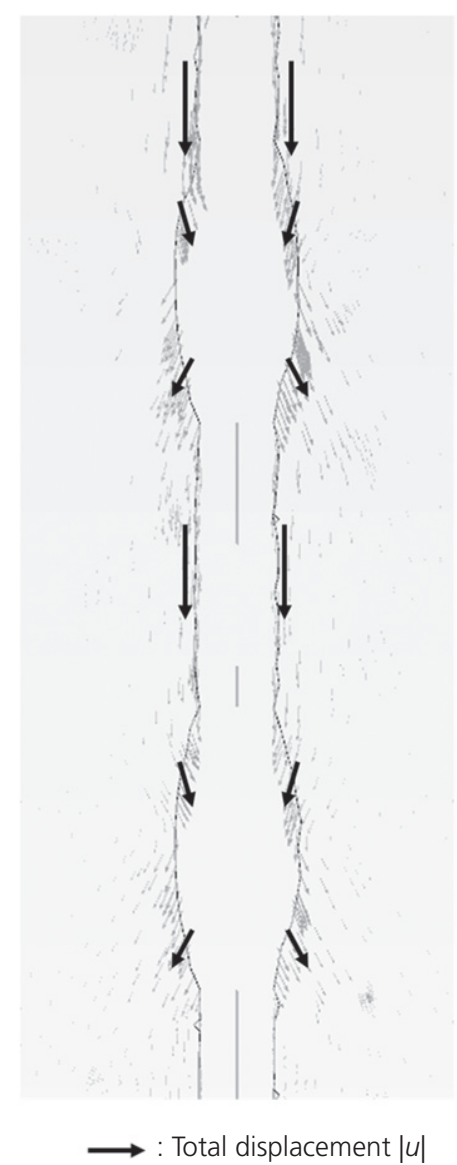

(a)

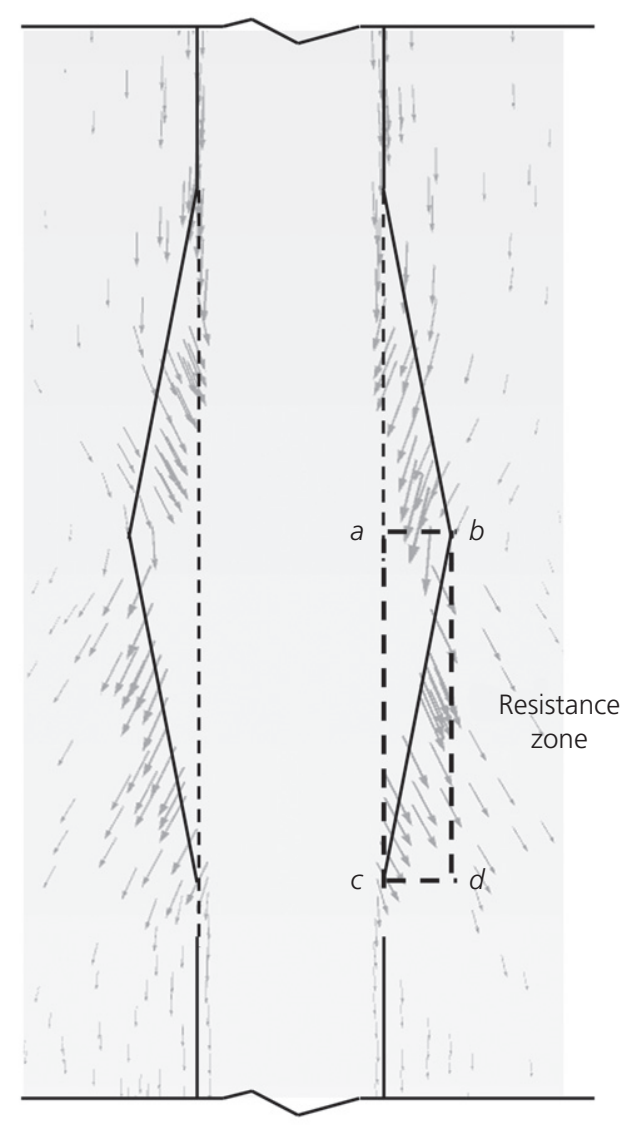

(b)

Fig. 4. Vertical load-bearing mechanism of the waveform micropile: (a) flow mechanism of total displacements, (b) resistance zones formed by the shear key

load develops below the shear keys located at certain depths. Therefore, this study proposes a predictive model for bearing capacity, considering both shaft resistance and the resistance by shear keys.

The resistance in the resistance zone below the shear key is divided into bearing resistance $Q_{\mathrm{B}}$ and shaft resistance $F_{\mathrm{N}}$ as shown in Fig. 5 according to the method for calculating the capacities of helical piles with a plate-type helix attached (Vickars \& Clemence, 2000; Elsherbiny \& El Naggar, 2013). The angle of the shear key with respect to the vertical is defined as $\alpha$.

On the basis of the Terzaghi (1943) equation for bearing capacities of shallow foundations, and considering an effective diameter that affects soil conditions and resistance at locations of shear keys, the bearing resistance $Q_{\mathrm{B}}$ in Fig. 5 is calculated as

$$
Q_{\mathrm{B} i}=\gamma^{\prime}{ }_{i} \frac{L_{i}}{2} h_{i} N_{\mathrm{q} i}\left(A_{1}-A_{2}\right)+\frac{1}{2} \gamma_{i}^{\prime} B_{i} N_{\gamma i}
$$

where $Q_{\mathrm{B} i}$ is the bearing resistance below the $i$ th shear key, $\gamma_{i}$ is the unit weight of the soil at the location of the $i$ th shear key, $L_{i}$ is the height of the $i$ th shear key in Fig. 1(b), $A_{1}$ is the cross-sectional area considering the diameter $\left(D_{1}\right)$ of the shear key, $A_{2}$ is the cross-sectional area of the shaft, $B_{i}$ is the effective diameter below the $i$ th shear key $\left(=\left(D_{1}-D_{2}\right) / 2\right)$ and $N_{\mathrm{q} i}$ and $N_{\gamma i}$ are the bearing capacity factors at the location of the $i$ th shear key, which can be calculated using the equations below (Meyerhof, 1951)

$$
N_{\mathrm{q} i}=\tan ^{2}\left(45+\frac{\theta_{i}}{2}\right) \mathrm{e}^{\pi \tan \theta_{i}}
$$

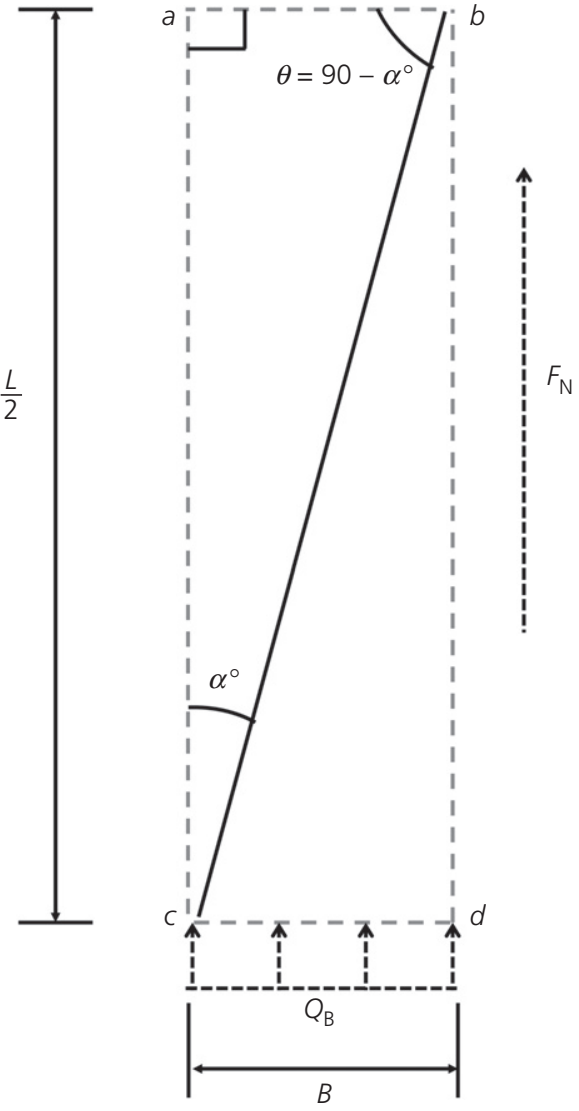

Fig. 5. Schematic diagram of acting forces on the shear key 
Table 3. $\alpha_{\text {bond }}$ values for sand suggested by the FHWA manual (FHWA, 2005)

\begin{tabular}{l|c|c|r|r}
\hline \multirow{2}{*}{ Description } & \multicolumn{4}{|c}{ Grout-to-ground bond ultimate strength: kPa } \\
\cline { 2 - 5 } & Type A & Type B & \multicolumn{1}{c}{ Type C } & Type D \\
\hline Sand (some silt) (fine, loose-medium dense) & $70-145$ & $70-190$ & $95-190$ & $95-240$ \\
Sand (some silt, gravel) & $95-215$ & $120-360$ & $145-360$ & $145-385$ \\
\hline
\end{tabular}

Type A: Gravity grout only.

Type B: Pressure grouted through the casing during casing withdrawal.

Type C: Primary grout placed under gravity head, then one phase of secondary 'global' pressure grouting.

Type D: Primary grout placed under gravity head, then one or more phases of secondary 'global' pressure grouting.

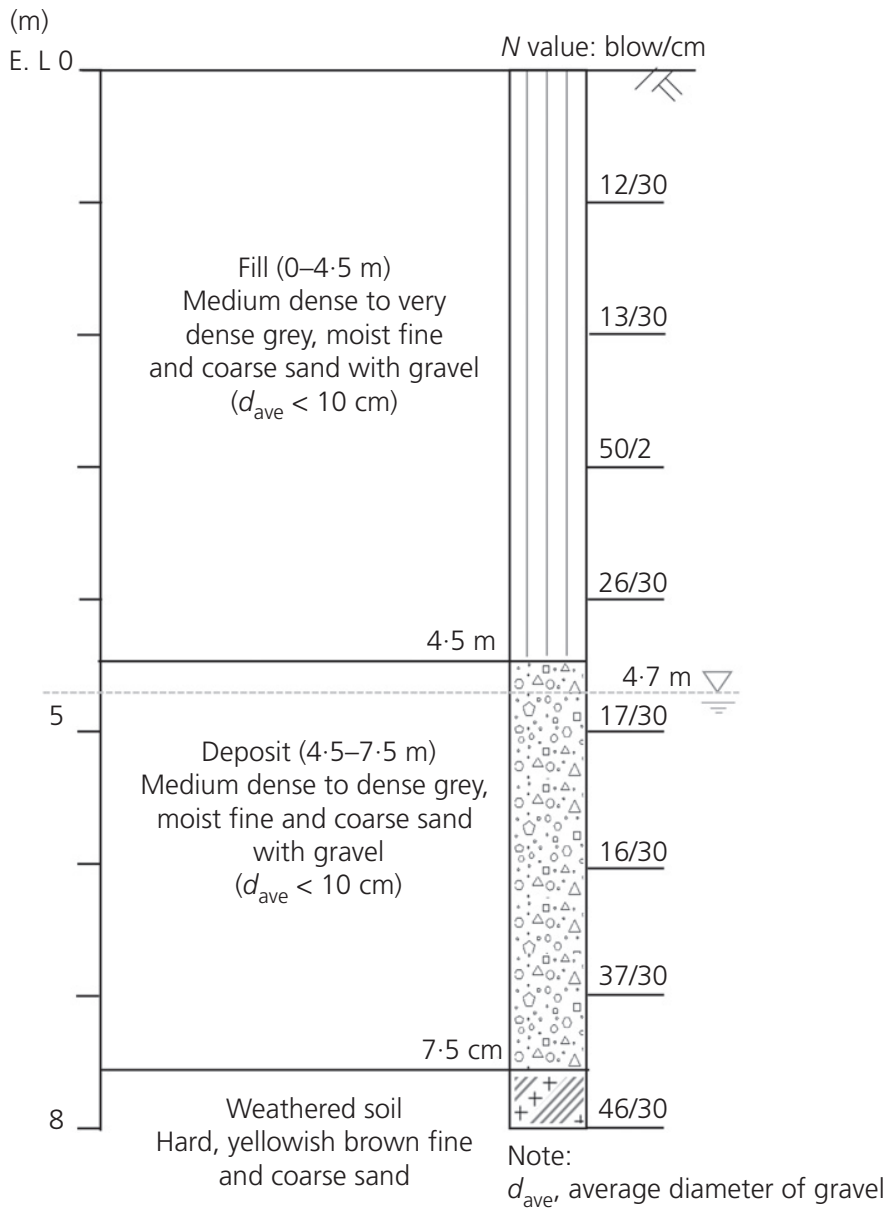

(a)

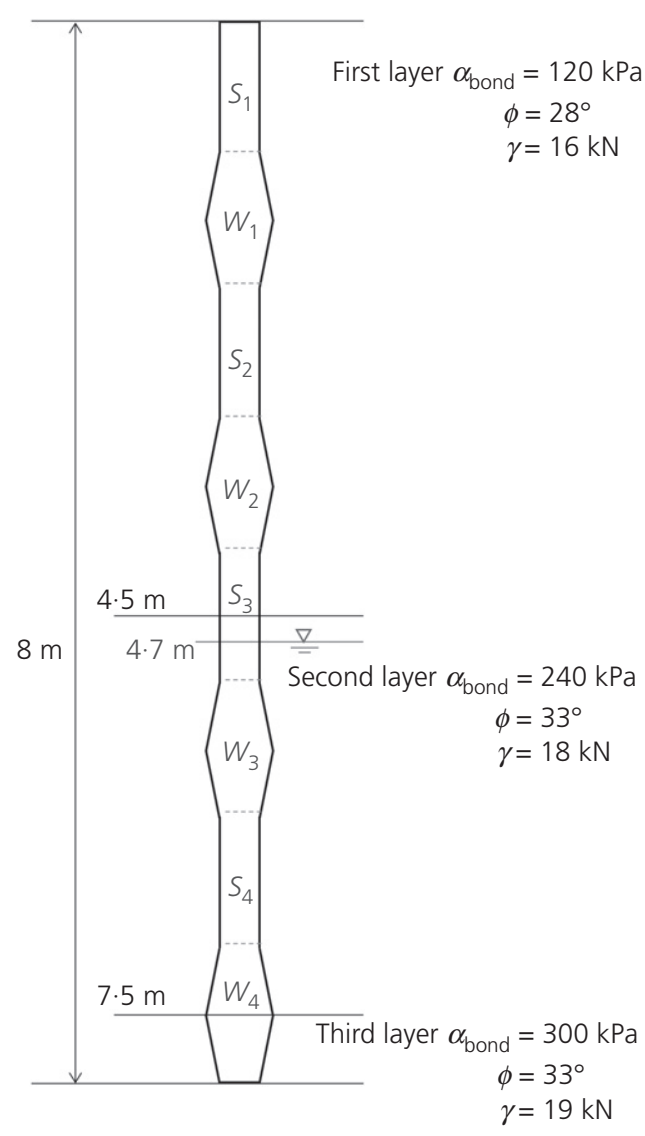

(b)

Fig. 6. Detailed conditions of the field test (Jang \& Han, 2018) used for the validation of the proposed calculation method: (a) ground condition, (b) input parameters for the pile sections

$$
N_{\gamma i}=\left(N_{\mathrm{q} i}-1\right) \tan \left(1 \cdot 4 \theta_{i}\right)
$$

where $\Phi_{i}$ is the internal friction angle of the soil layer at which the $i$ th shear key exists.

The shaft resistance, $F_{\mathrm{N}}$, is calculated using equation (4) based on the equation for shaft resistance of deep foundations, considering an internal friction angle, $\Phi_{i}$, of the soil contacting the resistance zone (Bowles, 1996)

$$
F_{\mathrm{N} i}=K_{i} \gamma^{\prime} h_{i} \tan \theta_{i} \pi D_{1} \frac{L_{i}}{2}
$$

where $K_{i}$ is the earth pressure coefficient at rest $\left(K_{\mathrm{o}}=1-\sin \Phi_{i}\right)$ for a depth of the $i$ th shear key and $D_{1}$ is the diameter of the shear keys.

For the shaft zone other than the shear keys, the ultimate bearing capacity of a micropile, $P_{\mathrm{u}}$, is calculated using
Table 4. Calculation results for a vertical design load using the field test data

\begin{tabular}{l|l|c|l|l|r|r}
\hline \multicolumn{2}{l|}{ Section } & $P_{\mathrm{U}}: \mathrm{kN}$ & \multicolumn{2}{c|}{ Section } & $F_{\mathrm{N}}: \mathrm{kN}$ & $Q_{\mathrm{B}}: \mathrm{kN}$ \\
\hline Shaft & $S_{1}$ & $113 \cdot 1$ & Shear key & $W_{1}$ & $7 \cdot 1$ & $77 \cdot 1$ \\
& $S_{2}$ & $113 \cdot 1$ & & $W_{2}$ & $14 \cdot 2$ & $136 \cdot 3$ \\
& $S_{3}$ & $169 \cdot 6$ & & $W_{3}$ & $20 \cdot 0$ & $329 \cdot 1$ \\
& $S_{4}$ & $226 \cdot 2$ & & $W_{4}$ & $25 \cdot 1$ & $545 \cdot 6$ \\
$\Sigma S$ & $622 \cdot 0$ & $\sum W$ & $66 \cdot 4$ & $1088 \cdot 1$ \\
$Q_{\mathrm{u}}=\Sigma S+\Sigma W=1776 \cdot 5 \mathrm{kN}\left(Q_{\text {Field }} * 1764 \mathrm{kN}\right)$
\end{tabular}

* Measured values from the field test.

equation (5) according to the design and construction manual for micropiles (FHWA, 2005)

$$
P_{\mathrm{u}}=\alpha_{\text {bond }} \pi D_{2} S_{i}
$$




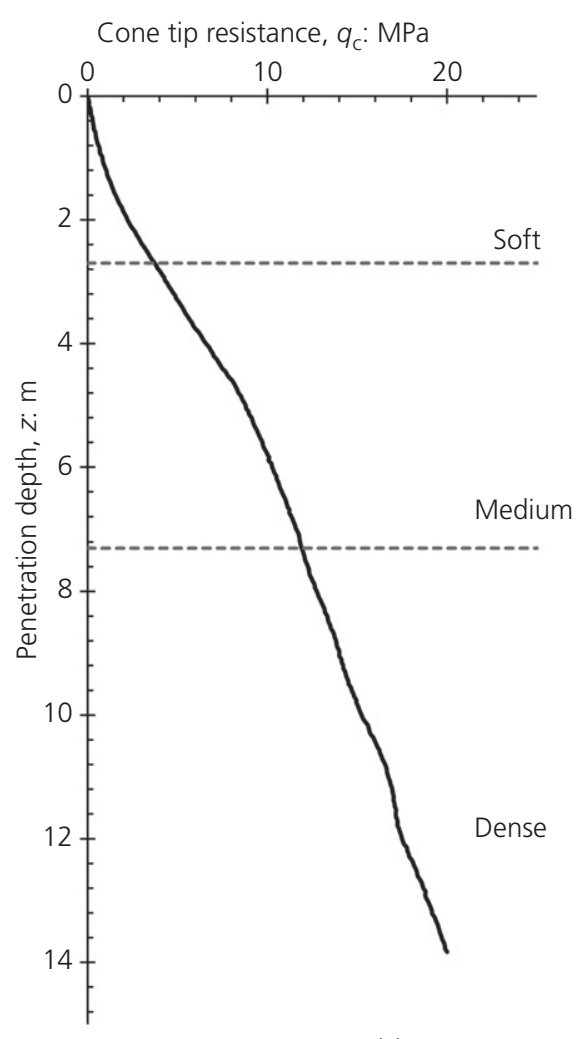

(a)

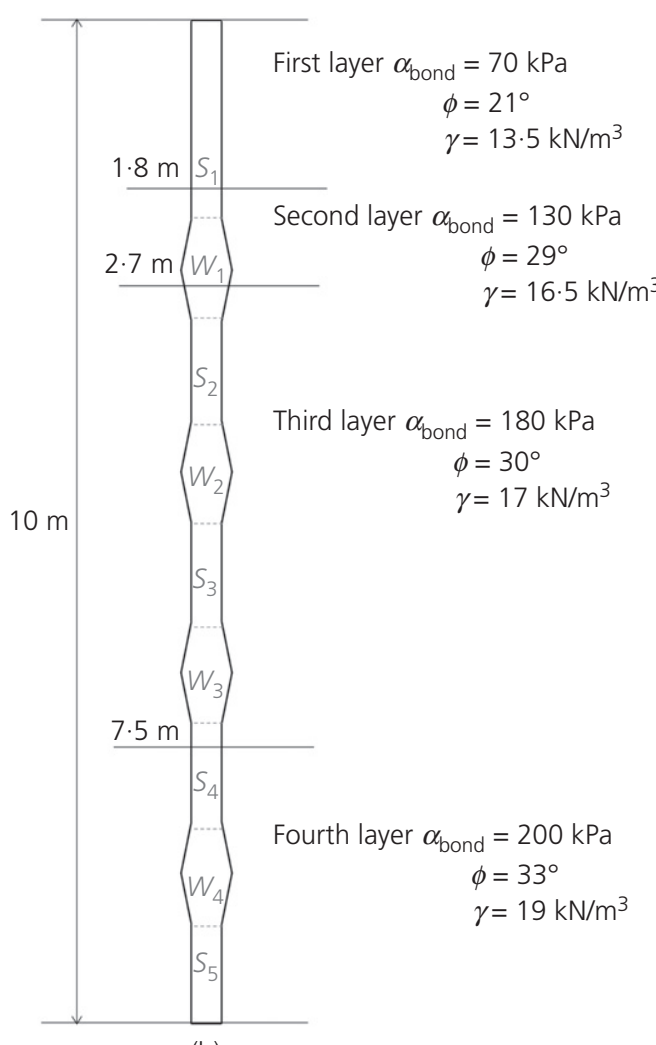

(b)

Fig. 7. Detailed conditions for the centrifuge test (Jang \& Han, 2019) used for the validation of the proposed calculation method: (a) ground condition, (b) input parameters for the pile sections

where $D_{2}$ is the diameter of a shaft, $S_{i}$ is the pile shaft length of the $i$ th layer in Fig. 1(b) and $\alpha_{\text {bond }}$ is the bond strength at the pile-ground interface. The $\alpha_{\text {bond }}$ is an important factor for determining design capacity, and it is determined based on the FHWA manual, considering grout construction methods such as gravity grouting (type A), pressure grouting (type B), multiple repeatable grouting (types C and D), pile socketing length and the type of soil layer.

Eventually, the ultimate bearing capacity, $Q_{\mathrm{u}}$, of a micropile is calculated using the conventional equation of the bearing capacity of a micropile (equation (5)), the equation for bearing resistance (equation (1)) and the equation for shaft resistance (equation (4))

$$
Q_{\mathrm{u}}=P_{\mathrm{u}}+Q_{\mathrm{B}}+F_{\mathrm{N}}
$$

\section{VALIDATION OF THE PROPOSED METHOD WITH THE EXPERIMENTAL RESULTS}

For validation, the ultimate bearing capacities of micropiles estimated by the proposed method were compared with the results of the field test and centrifuge test conducted by Jang \& Han (2018) and Jang \& Han (2019), respectively. For the calculations, the internal friction of the soil layer was estimated using the Dunham (1954) equation based on the $N$ value. Also, the $N$ value was estimated by referring to the CPT result for the centrifuge test. The $\alpha_{\text {bond }}$ corresponding to the ground condition was decided from Table 3 suggested by FHWA (2005).

Figure 6(a) shows details of the soil condition and the pile sections for the field test (Jang \& Han, 2018), which resulted in the ultimate bearing capacity of $1764 \mathrm{kN}$. The micropile can be divided into the shafts, $S_{1}-S_{4}$, and the four shear keys, $W_{1}-W_{4}$ as shown in Fig. 6(b). Therefore, the conventional micropile bearing capacity equation (equation (5)) was used for $S_{1}-S_{4}$, and the proposed
Table 5. Calculation results for a vertical design load using the centrifuge data

\begin{tabular}{l|l|c|l|l|c|r}
\hline \multicolumn{2}{l|}{ Section } & $P_{\mathrm{U}}: \mathrm{kN}$ & \multicolumn{2}{c|}{ Section } & $F_{\mathrm{N}}: \mathrm{kN}$ & $Q_{\mathrm{B}}: \mathrm{kN}$ \\
\hline Shaft & $S_{1}$ & $143 \cdot 3$ & Shear key & $W_{1}$ & $10 \cdot 5$ & $77 \cdot 5$ \\
& $S_{2}$ & $169 \cdot 6$ & & $W_{2}$ & $15 \cdot 6$ & $125 \cdot 1$ \\
& $S_{3}$ & $169 \cdot 6$ & & $W_{3}$ & $27 \cdot 0$ & $301 \cdot 8$ \\
& $S_{4}$ & $138 \cdot 9$ & & $W_{4}$ & $39 \cdot 7$ & $610 \cdot 4$ \\
$\Sigma S$ & $S_{5}$ & $188 \cdot 5$ & & & $92 \cdot 8$ & $1114 \cdot 8$ \\
\multicolumn{5}{l}{} & $809 \cdot 9$ & $\sum W$
\end{tabular}

*Measured values from the centrifuge test.

equations (1) and (4) were used for the shear keys. The estimated ultimate bearing capacity of $1776.5 \mathrm{kN}$ matches well with that from the field test. Table 4 summarises the resistance values calculated on the circular shafts and the shear keys.

In addition, Fig. 7 shows the result of the cone penetration test (CPT) of silica sand and pile sections used for the centrifuge test (Jang \& Han, 2019). The estimated ultimate bearing capacity of the waveform micropile from the centrifuge test was $2167 \mathrm{kN}$. Table 5 summarises the resistance values calculated for the shaft and shear key sections, and a total resistance of $2017 \cdot 4 \mathrm{kN}$. This calculated bearing capacity load is also similar to that measured by the centrifuge test.

\section{CONCLUSIONS}

To develop a predictive equation for bearing capacity, taking into account the increase of shaft resistance of the waveform micropile, this study developed a numerical model based on 
the field test conditions, and analysed the development of vertical resistance of the waveform micropile using the 3D FEM.

The numerical analysis revealed that the waveform micropile has a load resistance mechanism through shaft resistance around the circular shaft and resistance below the shear keys. Therefore, the factors that can consider the effects of shear keys were derived, and a new predictive equation considering this factor was proposed. Finally, the new bearing capacity equation for micropiles was validated using the results of a field test and a centrifuge test. The bearing capacities calculated by the proposed equation were in good agreement with those measured values from the tests.

\section{ACKNOWLEDGEMENTS}

This research was supported by a grant from the project titled, 'Development of technologies for structural safety on vertical extension for existing apartment buildings', which was funded by the Korea Institute of Civil Engineering and Building Technology (KICT).

\section{REFERENCES}

Bowles, J. E. (1988). Foundation analysis and design. New York, NY USA: McGraw-Hill Book Co.

Bowles, J. E. (1996). Foundation analysis and design, 5th edn. New York, NY, USA: McGraw-Hill Inc.

Brinkgreve, R. B. J., Engin, E. \& Swolfs, W. M. (2012). PLAXIS $3 D$ material models manual. Delft, The Netherlands: PLAXIS bv.

Dunham, J. W. (1954). Pile foundation for buildings. Proc. ASCE. Soil Mech. Found. Div. 80, No. 285, 1-21.

Elsherbiny, Z. H. \& El Naggar, M. H. (2013). Axial compressive capacity of helical piles from field tests and numerical study. Can. Geotech. J. 50, No. 12, 1191-1203.

FHWA (Federal Highway Administration) (2005). Micropile design and construction guidelines. Washington, DC, USA: US Department of Transportation.
Garbacz, A. (2010). Stress wave propagation throughout an interface: PCC composites-concrete substrate in repair system. $A C E E, 3$, No. 3, 35-44.

Jang, Y. E. \& Han, J. T. (2014). Development on the micropile for applying to artificial ground above railroad site. $A d v$. Sci. Technol. Lett. No. 55, No. 1, 43-46.

Jang, Y. E. \& Han, J. T. (2015). Study of load capacity of waveform micropile by centrifuge test. Proceedings of the 25th international offshore and polar engineering conference, Hawaii, USA (ed. J. S. Chung), pp. 21-26, Mountain View, CA, USA: International society of Offshore and Polar Engineers (ISOPE).

Jang, Y. E. \& Han, J. T. (2018). Field study on axial bearing capacity and load transfer characteristic of waveform micropile. Can. Geotech. J. 55, No. 5, 653-665.

Jang, Y. E. \& Han, J. T. (2019). Analysis of the shape effect on the axial performance of a waveform micropile by centrifuge model tests. Acta Geotech. 14, No. 2, 505-518.

Kim, S. H., Choi, J., Lee, J. M., Lee, J. \& Jung, C. Y. (2016). Improved load carrying behaviour of perfobond rib-installed partially expanded micropiles. Geotech. Test. J. 39, No. 4, 633-647.

Kitazawa, G., Takeyama, K., Suzuki, K., Okawara, H. \& Osaki, Y. (1959). Tokyo ground map. Tokyo, Japan, Gihodo Shuppan Co., Ltd., (in Japanese).

Livneh, B. \& El Naggar, M. H. (2008). Axial testing and numerical modeling of square shaft helical piles under compressive and tensile loading. Can. Geotech. J. 45, No. 8, 1142-1155, https://doi.org/10.1139/T08-044.

MCT (Ministry of Construction and Transportation) (2005). Korean highway bridge design code. Seoul, Republic of Korea: MCT (in Korean).

Meyerhof, G. G. (1951). The ultimate bearing capacity of foundations. Géotechnique 2, No. 4, 301-332, https://doi.org/ 10.1680/geot.1951.2.4.301.

Peck, R. B., Hanson, W. E. \& Thornburn, T. H. (1953). Foundation engineering. New York, NY, USA: John Wiley \& Sons.

Terzaghi, K. (1943). Theoretical soil mechanics, 2nd edn. New York, NY, USA: John Wiley and Sons.

Vickars, R. A. \& Clemence, S. P. (2000). Performance of helical piles with grouted shafts. In New technological and design developments in deep foundations (eds N. D. Dennis Jr, R. Castelli and M. W. O'Neill), pp. 327-341. Denver, CO, USA: American Society of Civil Engineers (ASCE). 